\title{
The effects of prefeeding in plain and chained fixed ratio schedules of reinforcement
}

RICHARD W. MALOTT

DENISON UNIVERSITY
The effects of prefeeding were studied using pigeons reinforced on either plain fixed ratio (FR) 64 or chained FR 32, FR 32 schedules of reinforcement. It was found that (1) the response rate increased as a function of the number of responses completed in the ratio, (2) the rate was higher for the chained FR group, (3) the rates decreased as a function of the amount prefed, (4) the latency of the first response in the rutio increased as a function of the amount prefed, (5) the prefeeding had a much greater effect on the rate in the first part than in the later part of the fixed ratio sequence, and (6) the prefeeding had a much greater effect on the response latency than on the response rate. It was concluded that the multiplicative rule of the effect of feeding schedules is inapplicable to behavior changes resulting from different segments of a single schedule of reinforcement.

Cumming, Berryman \& Nevin (1965) indicate that response rate is a multiplicative function of the feeding schedule. ${ }^{2}$ Stated symbolically,

$$
R_{i}=C \times R_{j},
$$

where $\mathbf{R}$ is the response rate, $\mathbf{i}$ and $\mathbf{j}$ indicate two different feeding schedules, and $\mathrm{C}$ is a constant. This implies that the ratio of the two rates equals a constant,

$$
\frac{\mathrm{R}_{\mathrm{i}}}{\mathrm{R}_{\mathrm{j}}}=\mathrm{C} \text {. }
$$

In other words, manipulation of a variable which affects the absolute value of the rates will leave the ratio unaffected;

$$
\frac{R_{i_{9} m}}{R_{j_{\Omega} m}}=\frac{R_{i, n}}{R_{j, n}}=C,
$$

where $m$ and $n$ indicate two different values of some other variable. Cross multiplication results in the following "corollary": The ratio of the response rate obtained under two different conditions of one variable is unaffected by changes in the feeding schedule;

$$
\frac{R_{i, m}}{R_{i, n}}=\frac{R_{j, m}}{R_{j, n}}=K \text {. }
$$

Most of the experiments which Cumming, Berryman and Nevin review in support of the multiplicative rule involve the use of schedules of reinforcement as the other variable which is manipulated. A class of variables other than schedules of reinforcement which might be manipulated is the degree of similarity between test and training stimuli in a stimulus generalization test; the rule does not seem to be applicable in that situation (Jenkins, Pascal, \& Walker, 1958; Thomas \& King, 1959). The present experiment is concerned with a test of the applicability of the multiplicative rule to the response rate in different segments of a single schedule of reinforcement; e.g. the first and last 16 responses of a fixed ratio 64 schedule of reinforcement.

Method

Eight Silver King pigeons at $70 \%$ ad lib weight and standard operant conditioning equipment were used. The chained fixed ratio (FR) group was exposed to the following schedule of food reinforcement: During the first component, $\mathrm{S}^{-}$, the pigeon response key was dark until $S$ waited for $30 \mathrm{sec}$. without responding. During the second component, $\mathrm{S}_{2}^{+}$, a horizontal white line was projected behind the key until the subject made 32 responses. During the final component, $\mathrm{S}_{1}^{+}$, a vertical white line was projected until the $S$ made 32 more responses. Then the food magazine was presented for 3 sec. and the key was darkened. The schedule of reinforcement for the plain FR group was the same except that the $\mathrm{S}_{2}^{+}$component was eliminated and the number of responses required in the $S_{1}^{+}$component was increased to 64 .

After the behavior had stabilized, the testing phase was begun. For three sessions, the Ss were not prefed, then for three sessions they were prefed $15 \mathrm{gm}$ of food; and finally for three sessions, they were prefed $30 \mathrm{gm}$. Prefeeding was done $3 \mathrm{hr}$. prior to the session.

In addition to the usual cumulative response records, two other measures were obtained by the use of running time meters: (1) the average latency of the first response following the offset of $\mathrm{S}^{-}$was recorded and (2) the 64 responses which intervene between $\mathrm{S}^{-}$and the reinforcement were divided into four blocks of 16 responses and the average response rate was computed separately for each of the four blocks (actually the rate for the first block of responses was computed using responses 2 through 16 since it is not meaningful to include the time required for the completion of the first response following $\mathrm{S}^{-}$).

\section{Results and Discussion}

Figure 1 shows that for both groups and all amounts of prefeeding, the response rate was a monotonically increasing function of the number of responses completed in the fixed ratio (cf. Thomas, 1964). For all blocks and all amounts of prefeeding, the response rate was higher for the chained than for the plain FR group; further research will be needed to determine the 


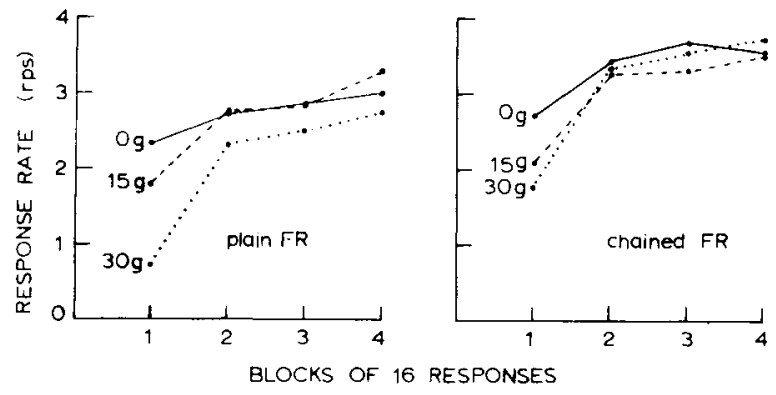

Fig. 1. Response rate as a function of the number of responses completed in the fixed ratio. For a given $S$, the mean response rate was computed for each block of 16 responses in the fixed ratio. and the median was then computed for each prefeeding phase. The medians of these data were then computed for each group and are shown in this figure.

variables responsible for the difference between this and earlier results (Thomas, 1964).

Although there was considerable overlap, the response rates clearly tended to decrease as the amount of prefeeding increased. That this is not apparent when examining only the cumulative response records may account for Sidman \& Stebbins' (1954) failure to find similar effects.

It can be seen in Table 1 that the latency of the first response following $\mathrm{S}^{-}$greatly increased as a function of the amount prefed (cf. Sidman \& Stebbins, 1954).

The multiplicative rule predicts that the ratio of the response rates obtained under two different feeding schedules is a constant, independent of other variables affecting the response rate. This would seem to imply that the ratio of the rates under either the 15 or 30 gm prefeeding schedule to the rates under the zero gram schedule should be independent of the number of responses completed in the fixed ratio. That the ratio was not constant is shown in Fig. 2. The prefeeding had a much greater effect in the first part of the fixed ratio of responses.

Table 1. The median latency ( $\mathrm{sec}$.) of the first response following $S^{-}$as a function of the amount pre-fed and the schedule of reinforcement. For a given $S$, the median latency was computed for each prefeeding phase. The medians of these data were then computed for each group and are the unbracketed figures in this Table. The figures in brackets are the ratios of the adjacent latency divided by the latency obtained with 0 grams prefeeding.

\begin{tabular}{lccc}
\multicolumn{4}{c}{ Amount Prefed $(\mathrm{gm})$} \\
\hline Group & 0 & 15 & 30 \\
\hline Ploin FR & 1.8 & $3.1(1.8)$ & $31.2(17.7)$ \\
Chained FR & 1.6 & $3.4(5.2)$ & $20.4(12.5)$ \\
\hline
\end{tabular}

Since the latency of the response is a similar measure to the rate of the response, it might also be expected that the multiplicative rule would be applicable here. If it does hold then the ratio of the response rate to the latency should be independent of the amount of prefeeding. That this was not the case is readily apparent by examining Table 1 and Fig. 2 . The response latency was much more affected by the prefeeding than was the response rate.

In conclusion, earlier research indicates thit the multiplicative rule of the effect of the feeding schedule is applicable to rate changes resulting from changes in the schedule of reinforcement, but not resulting from changes in the degree of similarity between test and training stimuli in a stimulus generalization test. The present experiment indicates that the rule is also inapplicable to different segments of a single schedule of reinforcement.

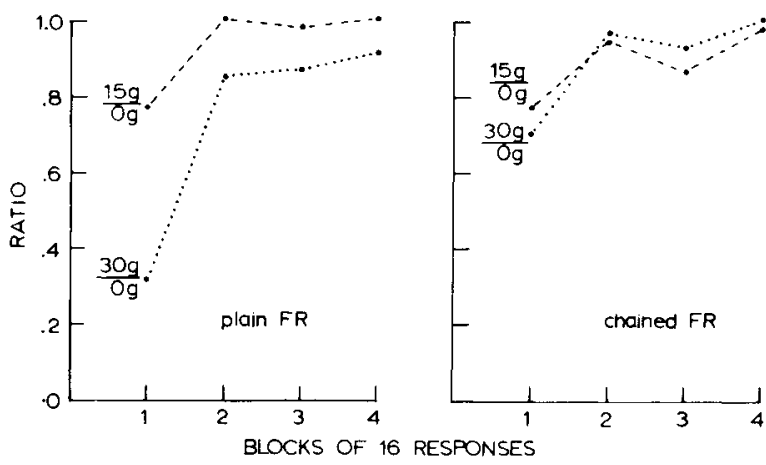

Fig. 2. Ratio of the response rates in the 15 and $30 \mathrm{gm}$ prefeeding phases to the rates in the 0 gram prefeeding phase. These ratios are computed from the data shown in Fig. 1.

\section{References}

Cumming, W. W., Berryman, R., \& Nevin, J, A. Search for an effect of satiation of delayed matching-to-sample performance. $P$ sychol. Rep., 1965, 16, 645-652.

Jenkins, W. O., Pascal, G. R., \& Walker, R. W., Jr. Deprivation and generalization. $J$. exp. Psychol., 1958, 56, 274-277.

Sidman, M., \& Stebbins, W. C. Satiation effects under fixed-ratio schedules of reinforcement. J. comp. physiol. Psychol., 1954, 47, $114-116$.

Thomas, D. R., \& King, R. A. Stimulus generalization as a function of level of motivation. J. exp. Psychol, 1959, 5, 323-328.

Thomas, J. R. Multiple baseline investigation of stimulus functions in an FR chained schedule. J. exp. Anal. Behav., 1964 , $7,241-245$.

\section{Notes}

1. This research was supported by Public Health Service Grant MH10755-01.

2. The feeding schedule is a function of the hours of deprivation, percent of normal body weight, and amount of prefeeding. The empirical concept of "feeding schedule" is used in order to avoid the hypothetical concept of "drive strength" and the implication that manipulation of the three above mentioned variables will of logical necessity produce the same results. 